\title{
Editorial: Journal of Statistical Distributions and Applications
}

Felix Famoye* and Carl Lee

\section{Introduction}

Statistical distributions are the foundations of statistical methodology in both theory and applications. They are the back bone of every parametric statistical method, including inference, modeling, survival, reliability, and others. In recent years, partly due to the advanced computing technology, there have been a series of developments of new methodology for generating new families of statistical distributions, which have greatly enhanced parametric statistical methods for handling real world scenarios that could not be modeled using existing distributions. One main reason for the need of generalized families is that each of the useful basic statistical distributions has its own weakness in real-world applications. The real-world phenomena are often much more complex for these commonly known basic statistical distributions to provide adequate fit. For example, Johnson et al. (2005) presented various modifications and generalizations of the Poisson distribution. Some of these distributions were developed in an attempt to explain the unequal mean and variance in the numerical data observed in different fields of applications.

The history of statistical distributions started in the $18^{\text {th }}$ century. The first major gathering on statistical distributions and their applications was in 1963 at McGill, Canada where experts participated in the International Symposium on Classical and Contagious Discrete Distributions. Another major gathering, the NATO Advanced Study Institute on Statistical Distributions in Scientific Work, was held at the University of Calgary, Canada from July 29 to August 10, 1974. Patil et al. (1974) in their preface to the Proceedings of the NATO Advanced Study Institute, referred to the McGill symposium as "a milestone in the recognition and development of the theory and application of statistical distributions." According to Professor Kotz in his Foreword to the book by Consul and Famoye (2006) "The main impetus for the development of an orderly investigation of statistical distributions and their applications was the International Symposium on Classical and Contagious Discrete Distributions, organized by G.P. Patil in August of 1969 (1963) ..." Since then, various conferences and meetings have been organized on statistical distributions. However, no dedicated journal on statistical distributions was ever launched.

In one of the Lukacs Symposia in the early 1990s held at Bowling Green State University, Bowling Green, Ohio, Dr. Adrienne Kemp (University of St. Andrews in Scotland) in her address stated that all research articles on statistical distributions are scattered in various journals and there is no dedicated journal for statistical distributions. To 
the best of our (Editors-in-Chief) knowledge, there is no journal that is currently devoted to the statistical distributions and their applications. Research articles in these subject areas are currently scattered in many different journals. It is the goal of Journal of Statistical Distributions and Applications (JSDA) to serve as an outlet for research work in the areas of statistical distributions. This will serve to fill the gap in the current publishing outlets.

\section{Reasons for starting the journal}

JSDA will serve as a main outlet for research work in statistical distributions. Currently, there is no designated journal on statistical distributions and their applications. As a consequence, with many journals serving as outlets to research in statistical distributions, there is a greater chance that similar research articles will be published by different journals years after the first article had appeared. This journal will help to reduce such duplication of research articles on statistical distributions. Readers of the journal will be able to ascertain the progress of and extent of knowledge in the area of statistical distributions.

JSDA will stimulate research in the area of statistical distributions and their applications. The journal will focus on the publications of new developments in statistical distributions as well as their innovative applications to different real world problems. To achieve this purpose, originality, quality and clarity in presentation will be part of the criteria used to judge and accept an article for publication.

JSDA will make theoretical and methodological advances in statistical distributions. Researchers will be able to extend and improve upon published methodological papers. This may lead to developing new methods that can compete with, or perform better than, the available methods. The quality and breadth of the editorial board members will help to achieve this purpose.

JSDA will provide an up to date review of interesting and current topics in statistical distributions. To achieve this purpose, the journal will publish review articles of significant nature. The journal will also publish special issues for conferences on current topics related to statistical distributions and their applications. An example is the publication of papers presented at the first International Conference on Statistical Distributions and Applications (ICOSDA), after the papers undergo rigorous peer review process. This conference was hosted from October 11-12, 2013 by Central Michigan University, Mt. Pleasant, Michigan.

\section{Editorial aims and scope}

JSDA is a peer-reviewed international journal for the publication of original articles of high quality that make significant contributions to statistical distributions and their applications. The scopes include, but are not limited to, development and study of statistical distributions, frequentist and Bayesian statistical inference including goodness-of-fit tests, statistical modeling, computational/simulation methods, and data analysis related to statistical distributions. Significant and well-written articles on theory and methods in areas of statistical distributions and their applications will be considered for publication.

\section{Conclusion}

Starting a journal of this nature is not an easy task. We gratefully acknowledge the support and guidance of Mr. Marc Strauss, Ms. Hannah Bracken, Mr. Sam Woodbridge 
and Ms. Lea Aludino of Springer. Without their strong support, this journal would not have been launched on schedule. Our sincere thanks and appreciation go to the editorial board members for their dedicated service and also to the reviewers for their diligent work to ensure rigor and quality in the papers that appear in the journal.

Received: 25 April 2014 Accepted: 8 May 2014

Published: 11 June 2014

\section{References}

Consul, PC, Famoye, F: Lagrangian Probability Distributions. Birkhäuser, Boston, USA (2006)

Johnson, NL, Kemp, AW, Kotz, S: Univariate Discrete Distributions, 3rd edn. Wiley, Hoboken, NJ (2005)

Patil, GP, Kotz, S, Ord, JK: A Modern Course on Statistical Distributions in Scientific Work, volume 2: Model Building and Model Selection. D. Reidel Publishing Company, Boston, USA (1974)

doi:10.1186/2195-5832-1-1

Cite this article as: Famoye and Lee: Editorial: Journal of Statistical Distributions and Applications. Journal of Statistical Distributions and Applications 2014 1:1.

Submit your manuscript to a SpringerOpen ${ }^{\odot}$ journal and benefit from:

- Convenient online submission

- Rigorous peer review

- Immediate publication on acceptance

- Open access: articles freely available online

- High visibility within the field

- Retaining the copyright to your article 